\title{
O uso das informações contidas em documentos de patentes nas práticas de Inteligência Competitiva:apresentação de um estudo das patentes da UFMG
}

Renata Cristina Teixeira

Mestranda em Tecnologia pelo CEFETRJ.Especialista em Gestão de Negócios e Inteligência Competitiva pela UNIRIO Especialista em Organização da Informação em Contexto Digital pela UFMG Bibliotecária pela UFMG. Analista de Inteligência Tecnológica do Centro de Pesquisas e Desenvolvimento (CENPES) da Petrobrás

Renato Rocha Souza

\begin{abstract}
Pós-doutorado em Tecnologias Semânticas para Recuperação de Informação na Glamorgan University, Reino Unido.Doutor em Ciência da Informação pela UFMG. Professor e Pesquisador da Escola de Matemática Aplicada (EMAp) da Fundação Getúlio Vargas
\end{abstract}

Este trabalho apresenta a Inteligência Competitiva (IC) como ferramenta minimizadora dos riscos, durante a tomada de decisão nas empresas. Apresenta o conceito de IC, seu histórico e seus processos. Apresenta o documento de patente, como fonte de informação de expressiva importância para recuperação de informações tecnológicas e, consequentemente, como ferramenta para as práticas de IC. Apresenta a análise do conhecimento protegido, através dos documentos de patentes depositados pela UFMG no Brasil e no exterior, publicados até novembro de 2012.

Palavras-chave: Inteligência competitiva; Informação tecnológica; Propriedade industrial; Patentes. 


\title{
The use of the information contained in patent documents in the Competitive Intelligence practices: a study of the patents of UFMG
}

\begin{abstract}
This paper presents the Competitive Intelligence (CI) as a tool for risk minimizing during the decision-making process. It presents the CI concept, its history and its processes. It features the patent document as an information source of great importance for technological information retrieving and, consequently, as a tool for CI practices. It presents the analysis of knowledge protected through patent documents filed by the Federal University of Minas Gerais in Brazil and abroad, published by November 2012.
\end{abstract}

Keywords: Competitive intelligence; Technological information; Industrial property; Patent.

Recebido em 14.04. 2011 Aceito em 08.02.2013

\section{Introdução}

Uma empresa competitiva é aquela que tem o domínio dos processos necessários ao negócio da companhia e que obtém respostas rápidas e precisas, de forma a tornar-se flexível e ágil, para aproveitar as oportunidades do mercado e se proteger das ameaças de seus concorrentes. A competitividade é a capacidade da empresa em ser mais produtiva e lucrativa dentro de seu universo competidor. É definida, muitas vezes, pela capacidade da empresa em tomar as melhores decisões, obtendo, assim, melhores resultados.

Mas, o contexto atual, exige muito para que a empresa acerte em suas decisões, visto a competitividade do mercado. Vive-se na era da Sociedade da Informação, que é caracterizada principalmente pela explosão informacional, que nos faz perdidos em meio a um emaranhado de dados e informações que, se não selecionados, podem causar o efeito contrário ao da obtenção de respostas. $E$, nesse contexto, a Inteligência Competitiva (IC) torna-se, ainda, mais importante, uma vez que objetiva minimizar ao máximo o risco por meio do suprimento informacional preciso, fazendo com que as organizações obtenham vantagem competitiva.

O ambiente de competição que se instalou no Brasil, a partir dos anos 90, exigiu que as empresas detivessem maior atenção aos seus concorrentes. Gomes e Braga (2006) narram que, a partir da abertura do 
mercado nacional às empresas de capital estrangeiro, as empresas brasileiras sentiram necessidade de desenvolverem melhores estratégias de negócio que as ajudassem a não perder espaço para a concorrência. Nesse momento, a IC aporta no país para subsidiar a tomada de decisão, utilizando-se de atividades de pesquisa e análise de informações, monitoramento e prospecção de mercados e tecnologias.

Dentre os vários insumos utilizados para as atividades da IC, os documentos de patentes foram escolhidos para discussão no presente trabalho. Documentos de patente podem ser considerados como fontes privilegiadas para o monitoramento do estado-da-arte, em termos de tecnologia, e uma fonte direta de indicativos para processos de inteligência competitiva e monitoramento da concorrência.

Segundo Mogee (1997), o documento de patente permite acesso público às informações detalhadas sobre invenções e fornece um direcionamento acerca de quais pesquisas são realizadas e quais empresas ou instituições têm investido esforços nelas. A IC analisa pontos do macro e micro ambientes organizacionais, como análise de situação técnica, as tendências tecnológicas, análise de concorrentes potenciais e demandas sociais, dentre outros. A análise das informações contidas em documentos de patente é um instrumento para mapear interações das organizações com seu ambiente de negócios.

Segundo Dou et al. (2005), as patentes são fontes de informação original, indicando a necessidade da análise prévia em documentos de patentes antes de qualquer suposição, conjectura ou hipótese. Os documentos de patentes, ou seja, os depósitos de patentes e as patentes concedidas, contêm a descrição detalhada da invenção e de suas reivindicações, isto é, exatamente o objeto que a patente deseja proteger. Essas informações refletem o nível tecnológico tanto de uma empresa isolada quanto de todo um país.

Segundo Federman (2006), não existe fonte de informação mais atual e completa que aquela descrita em um documento de patente, pois esta deve apresentar uma descrição do estado da técnica até a data do depósito. Isso pode ser afirmado com segurança, pois um pedido de patente deve ser descrito de tal forma que um técnico da área possa reproduzir o invento, o que faz com que esse documento contenha informações muito detalhadas da tecnologia nele descrita.

O presente estudo ressalta o documento de patente como fonte de informação imprescindível ao monitoramento e prospecção tecnológicos, tendo em vista a sua grande variedade de conteúdo, na qual muito desse conteúdo apenas é disponibilizado nesse tipo de documento. Também, apresenta o estudo da propriedade industrial protegida pela Universidade Federal de Minas Gerais (UFMG), através do estudo dos documentos de patentes dessa instituição, depositados no Brasil e no exterior, e publicados $^{1}$ até o final de novembro de 2012.

\footnotetext{
${ }^{1}$ Os pedidos de patentes são mantidos em sigilo por um período de 18 meses, contados da data de depósito ou da prioridade mais antiga, quando houver. Após esse período é publicado na Revista de Propriedade Industrial do INPI. O depositante pode requerer a antecipação da publicação de seu pedido.
} 


\section{Inteligência competitiva}

A IC trata da análise das informações sobre o mercado e da geração de recomendações para os decisores dentro das empresas. A informação é analisada, de forma minuciosa e com visão para o mercado em que a companhia está inserida, para que possa minimizar riscos durante o processo decisório. No mundo das corporações, a IC emergiu como uma ferramenta tática indispensável e importante em todos os seus detalhes.

A IC, a partir de processos sistemáticos de coleta, tratamento, análise e disseminação da informação sobre o ambiente competitivo, o concorrencial e o organizacional, visa subsidiar o processo decisório e atingir as metas estratégicas da organização (COELHO et al., 2002). Em outras palavras, a IC se preocupa com as informações que chegam até a empresa. Ela também se preocupa com a maneira como as informações saem da companhia, utilizando-se dos processos de contra inteligência, mas esse tema não consta do escopo do presente trabalho.

As atividades de IC derivaram-se das atividades de espionagem no período da Guerra Fria. Com o término da guerra, as pessoas que trabalhavam para os serviços de espionagem perderam suas funções e perceberam que utilizar suas habilidades de coletar e tratar informação, agora de forma ética e legal, daria às empresas uma forte vantagem competitiva. Foi, a partir de teorias e experiências inerentes à inteligência militar, que se desenvolveu o conjunto de conceitos, marcos referenciais e critérios analíticos utilizados com êxito na IC. (Pinheiro, 2005; Gomes e Braga, 2006).

Queyras e Quoniam (2006), sobre a IC, apresentam que, por meio dela, aperfeiçoam-se a coleta, a análise e a armazenagem da informação para produzir informações de alto valor agregado, propondo, dessa forma, soluções para as organizações que procuram manterem-se competitivas.

Nos Estados Unidos, foi criada em 1986, a Society of Competitive Intelligence Professionals (SCIP) (Sociedade dos Profissionais de Inteligência Competitiva), que oferece capacitação através de cursos e treinamentos, organiza eventos na área e promove rede de relacionamentos entre os profissionais de IC. Em seu código de ética, a SCIP reforça a IC como uma atividade ética, quando salienta que o profissional deve revelar toda informação importante, incluindo identidade e organização, antes de qualquer entrevista; respeitar integralmente todo pedido de confidencialidade da informação; e promover e encorajar o respeito total aos padrões éticos, em sua empresa e no desempenho da profissão.

No Brasil, as atividades de IC tiveram início na década de 1990, logo após a abertura do mercado nacional às empresas de capital estrangeiro. Segundo Gomes e Braga (2001), empresas inseridas em ambientes pouco ou muito competitivos conseguiram enxergar a IC como um instrumento que possibilita um conhecimento de maior qualidade de seus ambientes de negócios. 
A IC foi introduzida nas universidades em 1997, por meio do Curso de Especialização em Inteligência Competitiva (CEIC) ${ }^{2}$, realizado pelo Instituto Nacional de Tecnologia (INT) em parceria com o IBICT, a UFRJ, a Universidade de Marseille e algumas empresas, como a Petrobras e a Telebrás (PINHEIRO, 2005).

Em 2000, foi criada a Associação Brasileira dos Analistas de Inteligência Competitiva (ABRAIC), por um grupo de profissionais de várias organizações brasileiras, que realizaram cursos em nível de pósgraduação em IC no Brasil, na França e na Bélgica, e outros que já atuavam em áreas afins. Essa associação contribui para a disseminação da mentalidade de IC no país, ressaltando a prioridade da ética em suas atividades, assim como a SCIP o faz.

A IC tem como objetivo investigar o ambiente onde a empresa está inserida, apontando oportunidades e reduzindo riscos, aumentando as vantagens dessa empresa em relação as suas concorrentes. Queyras e Quoniam (2006) ressaltam que a IC deve criar efeitos de surpresa nos tomadores de decisão, permitir recolocar as ações no seu contexto e amenizar frustrações diante de interpretações difíceis ou contraditórias de certas informações.

\subsection{Processos de inteligência competitiva}

A metodologia da IC, segundo Coelho et al. (2002), repousa em um mecanismo simples: buscar a informação, considerando seu caráter formal e informal, a partir de táticas desenvolvidas de acordo com os objetivos estratégicos da empresa. Com as informações em mãos, dá-se início ao processo de análise das mesmas, que irá resultar em relatórios estruturados, dos quais sairão indicadores para os tomadores de decisão.

Lodi (2005) aponta a IC como um processo contínuo e interativo, que reúne recursos humanos e de tecnologia da informação, para coletar, analisar e disseminar informações relevantes, precisas e oportunas para a tomada de decisões na empresa.

O planejamento de IC é onde se define quais bases de conhecimento serão utilizadas, qual tipo de coleta será necessária (primária ou secundária), o cronograma da operação e a forma de apresentação dos resultados obtidos de acordo com o perfil do cliente. Passos (2005) relata que, nesse ponto do trabalho de IC, começa-se a construir redes de pessoas que farão o trabalho e desenvolverão as habilidades necessárias à produção de inteligência compreensível e comunicação eficaz.

Para a análise da informação, existem ferramentas que promovem a análise quantitativa, normalmente, fornecendo gráficos e quadros. A análise qualitativa das informações fica, ainda, a cargo de pessoas, os profissionais de IC. Esse é o ponto mais importante do trabalho de IC,

${ }^{2}$ O curso contou com a colaboração de professores estrangeiros, como Henri Dou e Luc Quonian (citado nesse trabalho), ambos da Université Aix-Marseille, França e com Alan Porter do George Institute of Tecnology, EUA. O professor Porter é o desenvolvedor de uma importante ferramenta de análise bibliométrica utilizada para prospecção tecnológica, o software VantagePoint, que trabalha com informação provenientes de bases de literatura ou patentes. 
devendo ser realizado por profissionais altamente capacitados. É muito importante que a equipe de IC tenha pleno conhecimento dos negócios da companhia e de seu planejamento estratégico. Esses conhecimentos nortearão todo o processo de IC. A inteligência é um processo, ou seja, é uma atividade que tem começo, meio e continuidade, não um fim.

Valentim (2003) aponta como ações da IC a prospecção e o monitoramento, a seleção e a filtragem, o tratamento e a agregação de valor, a disseminação e a transferência, a geração e o uso do ativo informacional e intelectual da organização. Gomes e Braga (2006) complementam as ações de IC citando a identificação dos pontos fortes e fracos ${ }^{3}$ do negócio da companhia.

A atividade de prospecção busca a identificação de informações e conhecimentos relevantes para os negócios da organização. Já a atividade de monitoramento, busca o acompanhamento das informações e dos conhecimentos produzidos e de relevância. As duas são, portanto, atividades complementares.

A prospecção tecnológica pode ser definida como um meio sistemático de mapear desenvolvimentos científicos e tecnológicos futuros, capazes de influenciar de forma significativa uma indústria, a economia ou a sociedade como um todo, como nos conta Kupfer e Tigre (2004). Os exercícios de prospecção são construídos a partir da premissa de que são vários os futuros possíveis, tentando preparar os atores na indústria para aproveitarem as oportunidades e enfrentarem as ameaças futuras e também intentando o desencadeamento de um processo de construção de um futuro desejável.

Prospecção significa uma compreensão maior sobre as forças que formulam o futuro e que devem ser levadas em conta nas decisões. Ela faz uso de pesquisa ou busca apurada com o objetivo de encontrar algo novo. A prospecção busca novos mercados, parceiros e clientes para a organização.

O SEBRAE ${ }^{4}$ define monitoramento como um serviço de informação que objetiva acompanhar o desenvolvimento tecnológico, os concorrentes, a clientela, os fornecedores de mercado e a ambiência social política, econômica e cultural, visando orientar estrategicamente uma empresa ou organização, em suas decisões de negócios.

O monitoramento tecnológico aponta as rotas de evolução de uma determinada tecnologia (produto ou processo) ao longo do tempo ou em uma determinada região.

O trabalho de IC requer continuidade, como já mencionado. Com o monitoramento regular de atuais e futuros concorrentes e das tendências e descontinuidades do mercado, possíveis oportunidades ou ameaças são percebidos em longo prazo. O profissional "aprende" a identificar essas variáveis à medida que conhece melhor o campo de atuação da empresa e

\footnotetext{
${ }^{3}$ As autoras se referem a uma ferramenta estratégia, a análise SWOT (strengths, weaknesses, opportunities e threats). A matriz SWOT é elaborada para focar a síntese dos cenários, estudo de mercado e análise competitiva; sintetizando os pontos fortes, pontos fracos, oportunidades e ameaças para a organização.

4 Serviço de Apoio às Micro e Pequenas Empresas. Disponível em: <http://www.sebraesc.com.br/sebraetib/hp/conceitos/info tec/monitoramento.htm>. Acesso em: 22 mar. 2007.
} 
sua cadeia produtiva. A IC pode fornecer cenários de possibilidades à empresa, pode atender a uma necessidade ou a uma questão muito específica e precisa ou pode, ainda, auxiliar a organização a aliviar ou anular o efeito de uma crise (CASTRO, 2007).

As empresas e universidades são, muitas vezes, medidas pela comunidade por meio das tecnologias e avanços científicos que estas apresentam à sociedade na forma de produção de tecnologias descritas em patentes e pela publicação do conhecimento em meios formais de divulgação científica e tecnológica. Essa cobrança deve ser levada em consideração, mas deve ser medida, pesada e avaliada, pois nem tudo deve ser publicado (às vezes, é melhor que seja patenteado) ou nem tudo deve ser patenteado. No caso de empresas, é importante ressaltar que certas tecnologias, por fazerem parte da estratégia corporativa, devem ser de detenção exclusiva da companhia, o que é denominado de segredo industrial

\section{0 documento de patente}

A lei assegurará aos autores de inventos industriais privilégio temporário para sua utilização, bem como proteção às criações industriais, à propriedade das marcas, aos nomes de empresas e a outros signos distintivos, tendo em vista o interesse social e o desenvolvimento tecnológico e econômico do País ${ }^{5}$.

Pela análise de documentos de patentes, pode se investigar: quais foram as patentes depositadas por uma companhia em um tempo determinado ou em toda a sua trajetória; quais as áreas tecnológicas são do interesse de uma companhia; quais as companhias ou indivíduos que estão patenteando numa área tecnológica específica; e a estratégia de mercado de uma companhia. Essas informações coincidem com os aspectos mais comumente utilizados para caracterização do panorama tecnológico da concorrência, daí a sua utilidade para processos de IC. Essas alternativas permitem ao analista em IC traçar uma verdadeira radiografia da tecnologia, mapear mercados potenciais, antecipar possíveis pendências judiciais decorrentes de danos a direitos de terceiros, conhecer o desenvolvimento tecnológico de um processo ou produto industrial ou estabelecer critérios de pesquisa para avanços tecnológicos sobre esses desenvolvimentos.

Os governos concedem patentes a fim de incentivar os inventores a compartilharem os segredos de suas descobertas. Como compensação por tornar público o seu segredo, o inventor ganha um monopólio sobre a invenção por um determinado período de tempo.

Uma patente deve ser depositada para assegurar o direito do autor ao uso e a comercialização de seu invento. Segundo o artigo $8^{\circ}$. da Lei no. 9.279 (BRASIL. Congresso Nacional, 1996) é patenteável a invenção que

${ }^{5}$ BRASIL. Constituição (1988). Constituição da República Federativa do Brasil, 1988. São Paulo: Atlas, 1988. $180 \mathrm{p}$. 
atenda aos requisitos de novidade, atividade inventiva e aplicação industrial. Sem esses três requisitos, uma patente não será concedida.

O termo documento de patente abrange tanto os pedidos de patentes, que são os documentos depositados pelo inventor, pelo qual este pleiteia a posse da invenção, quanto às patentes concedidas, que são os documentos finais após toda a tramitação dos pedidos de patentes, ou seja, a patente efetivamente. A patente pode ser concedida a uma invenção propriamente dita, a uma adição de invenção e a um modelo de utilidade.

Federman (2006) apresenta que uma patente se refere a qualquer invenção ou aperfeiçoamento que tenha uma utilização industrial. Oliveira et al. (2005) define patente como uma proteção legal, temporária, concedida pelo Estado ao inventor ou ao seu titular, dando a este o direito de impedir terceiros de usar, produzir ou realizar qualquer atividade comercial com o bem protegido, sem o seu consentimento.

A patente tem a função de proteger o invento contra a exploração comercial por terceiros, embora essa proteção seja temporária. No caso da patente de invenção, o prazo determinado por lei é de 20 anos a partir da data de depósito e de pelo menos 10 anos de vigência após a concessão. No caso da patente de modelo de utilidade, o prazo é de 15 anos e pelo menos oito anos após a concessão. Após esse prazo de vigência de exploração, o conteúdo da patente é totalmente disponibilizado ao uso pela sociedade, passando a tecnologia a ser de domínio público.

Nem toda tecnologia é patenteada pela empresa que a desenvolve. Algumas são mantidas como segredo industrial. Essa prática tem duração indeterminada, podendo se estender a longos períodos ou a períodos muito curtos em função de práticas de pesquisa de engenharia reversa. Nesse caso, a maior preocupação, além da descoberta pela empresa concorrente, seria o depósito de uma patente. Isso poderia impedir o inventor de utilizar sua própria descoberta, uma vez que a patente permite que terceiros sejam excluídos de atos relativos à matéria protegida.

O documento de patente possui a seguinte estrutura:

a) folha de rosto com informações bibliográficas;

b) relatório descritivo;

c) reivindicações;

d) desenhos (se for o caso); e

e) resumo.

\subsection{Folha de rosto}

$\mathrm{Na}$ folha de rosto, estão descritas as informações bibliográficas a respeito da patente. Nela, constam o depositante e o inventor (quando estes não desejam se omitir), a data de depósito, o país de origem, a 
classificação internacional e um breve resumo. A Figura 1 apresenta a folha de rosto de uma patente.

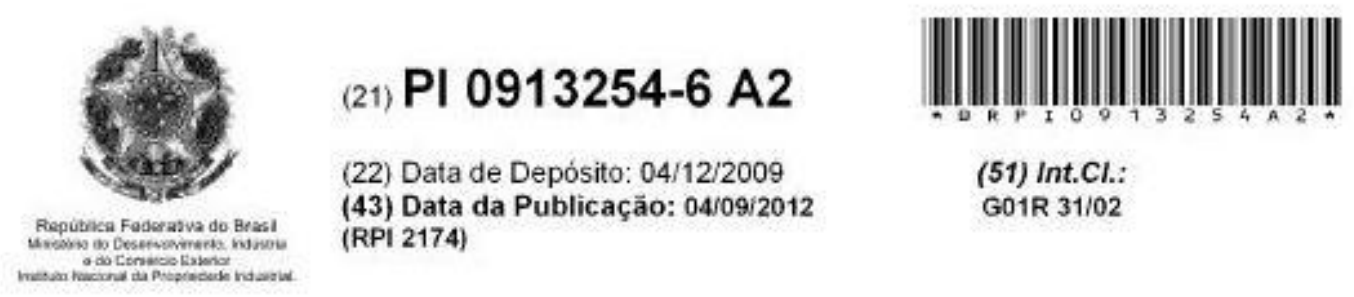

\section{(54) Titulo: DISPOSITIVO PARA DISGNÓSTICO DE FALHAS EM TRANSFORMADORES DE DISTRIBUIÇĀO E MÉTODO}

(73) Titular(es): Cemig D Distribulçăo S.A. Universidade Federa de Minas Gerais

(72) Inventor(es): Daniel Lúcio de Souza Borba, Erivaldo Costa Couto, Porfirio Cabaleiro Cortizo. Wallace do Couto Boaventura. Walmir Matos Caminhas. Elice Fernando de Melo. Elice Fernando de Melo
(57) Resumo: DISPOSITIVO PARA DIAGNOSTICO DE FALHAS EM TRANSFORMADORES DE DISTRIBUICCĀO E METODO A presente invença ro refere-se a um equipamento leve, compacto.robusto. da fácil utilizaçáo. alimentado por uma bateria. que pode, inclusive, ser a do proprio veiculo automotor responsavel pelo atendimento da ocorréncia para ser utilizado em campo por um elefricista, e que realza o diagnóstico da condiçáo operativa dos transformadores de distribuiçắ. Estando esse transformador em uma rede cuja proteçao primarria tenha atuado, näo há a necessidade de se desconectar o enrolamento secundario. A confiabilidade no resultado desses testes, éconsideravelmente incrementada, pois o núcleo de processamento desse equipamento id baseado em inteligência computacional, obtida a partir do processamento digital de sinais realizado por sofware dedicado embutido em um disposittivo Controlador Digital de Sinais - DSC.

Figura 1 - Folha de Rosto de um documento de patente

Fonte: Base de patentes do Espacenet. Disponível em:

$<$ http://worldwide.espacenet.com/publicationDetails/originalDocument?CC=BR\&NR=PI0913254A2\&K

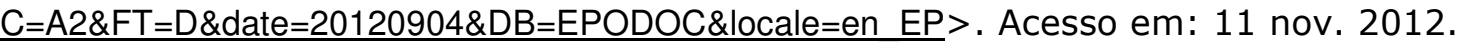

Os campos dos documentos de patentes seguem uma numeração padronizada internacionalmente, o INID ${ }^{6}$. Isso assegura que, mesmo que não se conheça o idioma do documento, seja possível a identificação dos campos. Esses códigos identificam todas as informações que constam da primeira página ou folha de rosto.

\subsection{Relatório descritivo}

No relatório consta a descrição do estado da técnica e seus problemas que motivaram o esforço inventivo. Apresenta a descrição detalhada da matéria pleiteada e sua melhor forma de realização. Segundo o art. 24 da Lei no. 9.279 (BRASIL. Congresso Nacional, 1996), o relatório deverá descrever clara e suficientemente o objeto, de modo a possibilitar sua realização por técnico no assunto e indicar, quando for 0 caso, a melhor forma de execução.

\subsection{Reivindicações}

Nas reivindicações, constam as informações de exatamente o que será protegido. Segundo o art. 25 da Lei no. 9.279 (BRASIL. Presidência da República, 1996), as reivindicações deverão ser fundamentadas no

\footnotetext{
6 Agreed Numbers for the Identification of Data (Código internacional para identificação de dados bibliográficos).
} 
relatório descritivo, caracterizando as particularidades do pedido e definindo, de modo claro e preciso, a matéria objeto da proteção. O art. 41 da mesma lei diz que a extensão da proteção conferida pela patente será determinada pelo teor das reivindicações, interpretado com base no relatório descritivo e nos desenhos.

\subsection{Desenhos}

No caso da existência de desenhos, estes devem conter clareza suficiente de modo a possibilitar sua reprodução, devem ser feitos em escala que possibilite sua redução e, também, ser executados, preferencialmente, com auxílio de instrumentos técnicos.

Os desenhos ou fluxogramas do processo pleiteado devem ser isentos de textos e cores e devem conter sinais de referência constantes do relatório descritivo. Federman (2006) ressalta que, no caso de Modelo de Utilidade, é imprescindível a apresentação de desenhos, uma vez que será analisado seu aspecto funcional.

\subsection{Resumo}

O resumo deverá ser um sumário do que foi exposto no relatório descritivo, nas reivindicações e nos desenhos. Deve servir de instrumento eficaz tanto para o examinador quanto para 0 pesquisador no entendimento da matéria que está sendo analisada.

\section{Utilização de patentes como fonte de informação tecnológica para IC}

O documento de patente, devido a todas as suas características, é uma excelente fonte de informação para o suporte às atividades de IC. Pela análise das informações contidas nos documentos de patentes é possível identificar o estado da técnica, evitando-se a mera repetição de esforços e pesquisas já realizados anteriormente. Isso inclui tecnologias que já pertencem ao domínio público. Pela identificação de rotas tecnológicas, é possível antever desenvolvimento de atividades industriais futuras antes que seus efeitos venham a se refletir no mercado de atuação. A identificação de atores no universo de interesse tecnológico da empresa pode determinar além dos atuais e futuros concorrentes ${ }^{7}$, futuros parceiros, licenciadores e consultores.

Segundo Gullo e Guerrante (2004, p. 6):

A relação entre as atividades de $P \& D$ medidas por indicadores de dispêndio de recursos, o número de pesquisadores e de pessoal envolvido na atividade de patenteamento é muito importante, uma vez que tais fatores representam aspectos centrais do processo de inovação. Além disso, um dos aspectos mais relevantes e vantajosos do uso de indicadores

\footnotetext{
${ }^{7}$ Novos entrantes no mercado.
} 
de patentes é o fato de que os dados de patentes cobrem todos os campos do conhecimento, o que o torna muito útil para a análise da difusão de tecnologias chaves, ou para a geração de perfis de especialização das entidades depositantes.

Pela análise dos documentos de patentes é possível encontrar subsídios que suportem a decisão de licenciar ou não uma tecnologia existente para a resolução de problemas técnicos e outros. Ideias inovadoras e totalmente disruptivas podem ser originadas a partir do estudo de uma tecnologia existente.

A quantidade de documentos de patentes que são depositados todos os anos tem crescido substancialmente. Segundo a World Intellectual Property Organization (WIPO, 2011), em 2010, foram depositados 909.000 documentos de patente em todo o mundo, a tendência é de crescimento. Federman (2006) aponta que um estudo da WIPO revelou que $70 \%$ de toda a tecnologia existente têm divulgação exclusiva por meio de patentes.

Outro fator determinante é a abrangência. Os documentos de patentes abrangem todos os campos tecnológicos, além de terem fácil acessibilidade. Atualmente, as coleções de documentos completos centralizadas em escritórios nacionais ou regionais de patentes têm acesso disponibilizado por meios eletrônicos. Ainda, contam com uma classificação internacional, que pode ser utilizada como critério objetivo para acessar documentos relevantes

\section{Estudo da propriedade industrial protegida pela UFMG}

$O$ incremento de novas tecnologias estimula as empresas a inovarem, o que gera um ciclo contínuo de desenvolvimento e que beneficia de forma direta a todos os atores do mercado. Segundo Gullo e Guerrante (2004), mais do que a acumulação quantitativa de conhecimento é a transformação qualitativa, que sugere novas perspectivas para o desenvolvimento econômico e social de um país.

Nunes e Oliveira (2007, p. 1) apontam que, dentre as consequências resultantes do desconhecimento do sistema de propriedade industrial pelas instituições de ensino superior no Brasil, cita-se:

[...] como exemplo, a não apropriação de tecnologias patrocinadas com recursos públicos, a falta de remuneração e reconhecimento aos pesquisadores pelos desenvolvimentos realizados, a ausência de divulgação para a sociedade do acervo tecnológico produzido e existente na Academia, bem como o crescente dispêndio das empresas com a aquisição de tecnologias exógenas.

Quando uma universidade opta pelo depósito de patentes, está promovendo a proteção de seus inventos que podem ter aplicações 
comerciais pelas empresas e, assim, como na publicação de artigos, está promovendo a transferência de conhecimento tecnológico e a utilização das informações disponíveis na documentação de patentes, que constitui como exposto no presente trabalho uma fonte de informação importante para o desenvolvimento de novas pesquisas.

\subsection{Evolução dos documentos de patentes publicados}

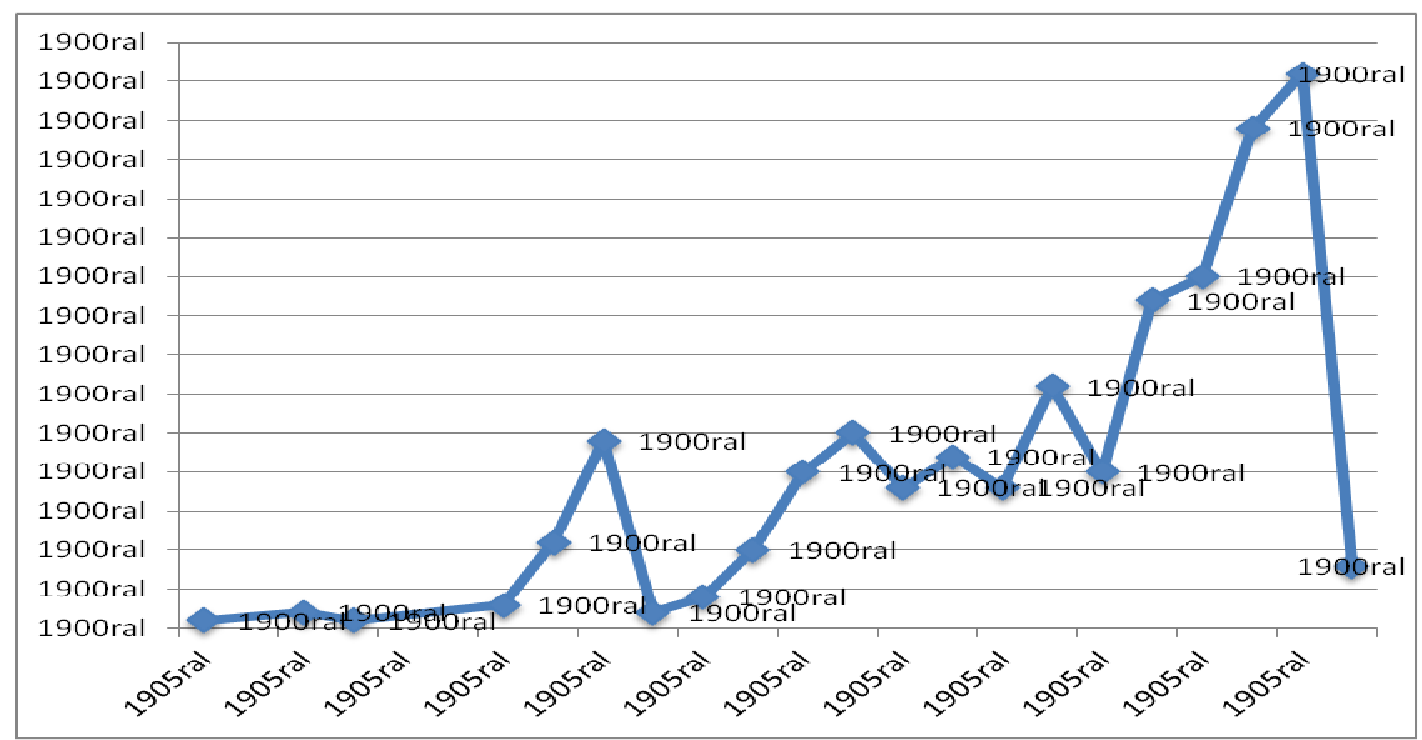

Gráfico 1 - Depósito de patentes por ano

Fonte: Elaboração própria a partir dos dados recuperados na base de patentes do INPI.

A proteção do conhecimento produzido pela UFMG teve seu início em 1989, com o depósito de uma patente de modelo de utilidade (MU6901600-3), que descreve uma "Câmara de microondas, adaptada para processos químicos laboratoriais". Desde então, percebe-se a crescente atenção por parte da instituição em proteger seus inventos. 0 Gráfico 1 apresenta a evolução dos depósitos de pedidos de patentes. Apenas os anos de 1993 e 1994 não registraram nenhum depósito. A partir do ano de 2008, observa-se um intenso crescimento no número de depósitos de patentes, com pico em 2011.

A queda no gráfico, no ano de 2012, não indica desinteresse por parte da Instituição na proteção de sua tecnologia. Essa aparente queda é o reflexo do período de sigilo que é de 18 meses. Apenas os registros que pediram antecipação de publicação constam no presente estudo. 


\subsection{Perfil dos documentos depositados pela UFMG}

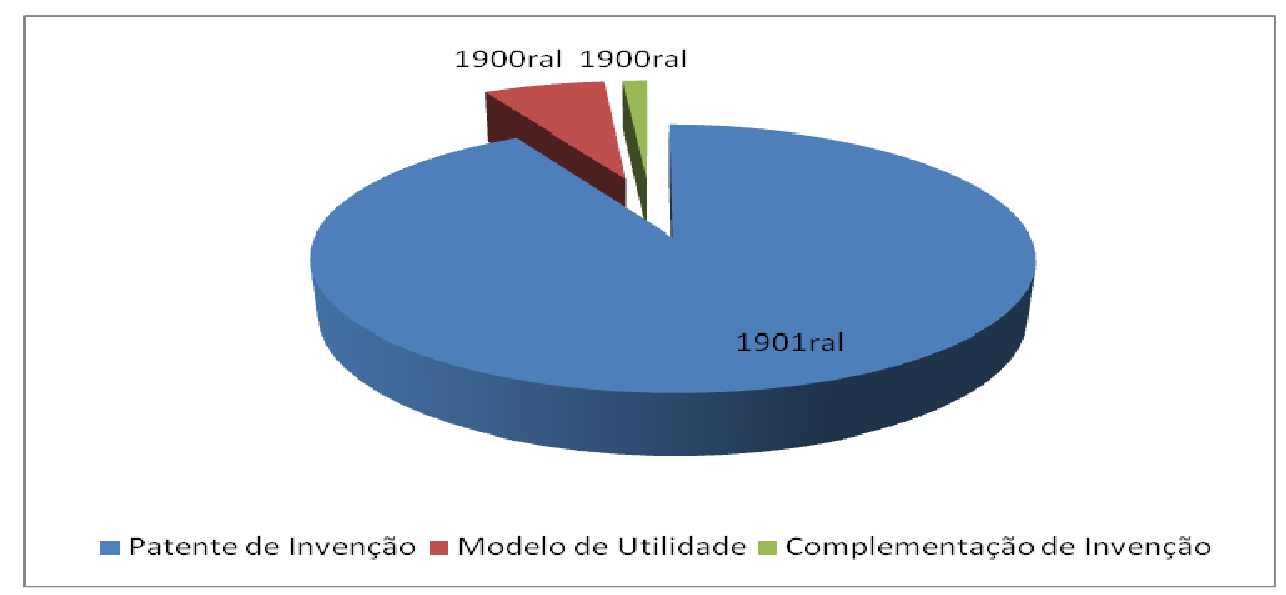

Gráfico 2 - Perfil de documentos depositados

Fonte: Elaboração própria a partir dos dados recuperados na base de patentes do INPI.

Quanto ao perfil dos depósitos da UFMG, foi identificado que, a grande maioria dos 444 documentos publicados, é composta por patentes de invenção, que representam $92 \%$ dos depósitos. Esse tipo de documento indica trabalhos provenientes de pesquisas, ou seja, desenvolvimento de novas tecnologias. As patentes de modelo de utilidade, que são os aperfeiçoamentos em objetos e instrumentos, representam apenas $7 \%$ do total dos depósitos. Por fim, apenas $1 \%$ dos depósitos se refere a complementos de invenção, como demonstrado pelo Gráfico 2.

\subsection{Mercados de interesse da UFMG}

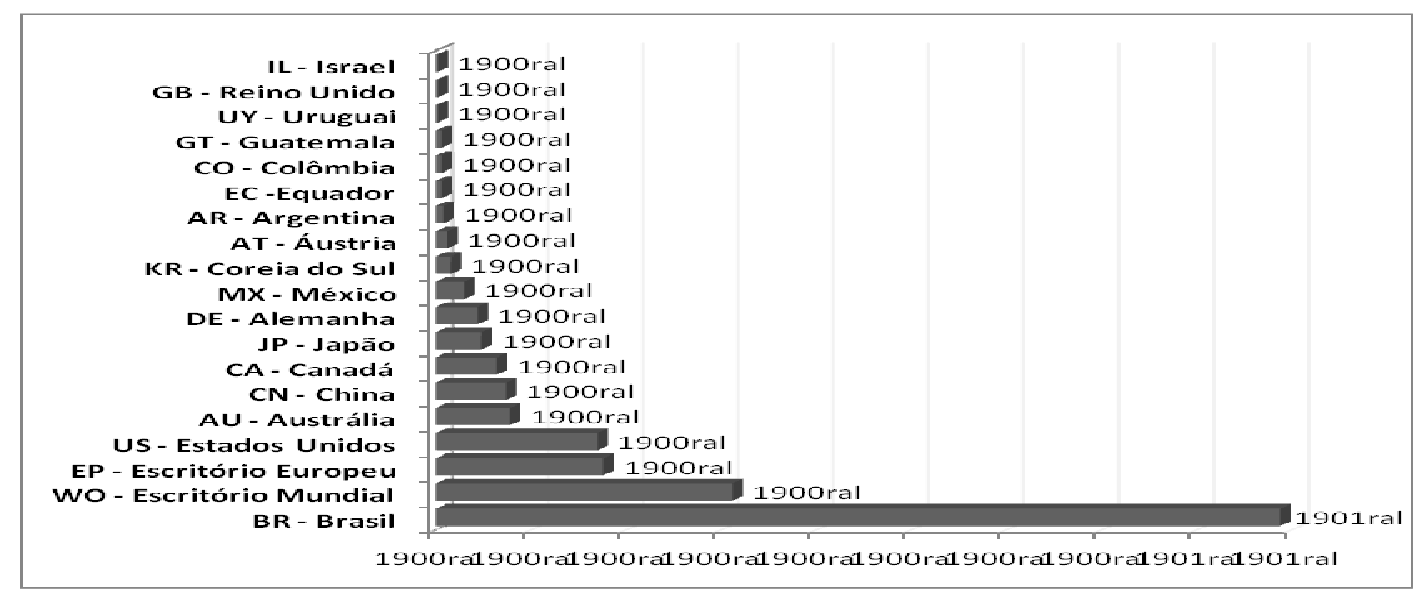

Gráfico 3 - Número de Depósitos por Escritório

Fonte: Elaboração própria a partir dos dados recuperados na base de patentes do INPI.

A análise das famílias de patentes é importante, pois explicita os possíveis mercados de interesse para a comercialização das tecnologias, segundo seus desenvolvedores. O Gráfico 3 mostra quais foram os países 
escolhidos para proteção tecnológica pela UFMG. O número elevado de depósitos, no escritório mundial, pode ser a indicação que mais países serão alvo de mercado pela universidade, uma vez que o depósito realizado, no escritório mundial, permite que seu titular possa solicitar, em um prazo de até 36 meses, a proteção de seu invento em qualquer dos 185 países que fazem parte da WIPO (dados de 2012). Quando se procura a proteção em mais países, o depósito via escritório mundial é uma solução economicamente viável.

\section{4 Áreas de interesse no desenvolvimento de tecnologias pela UFMG}

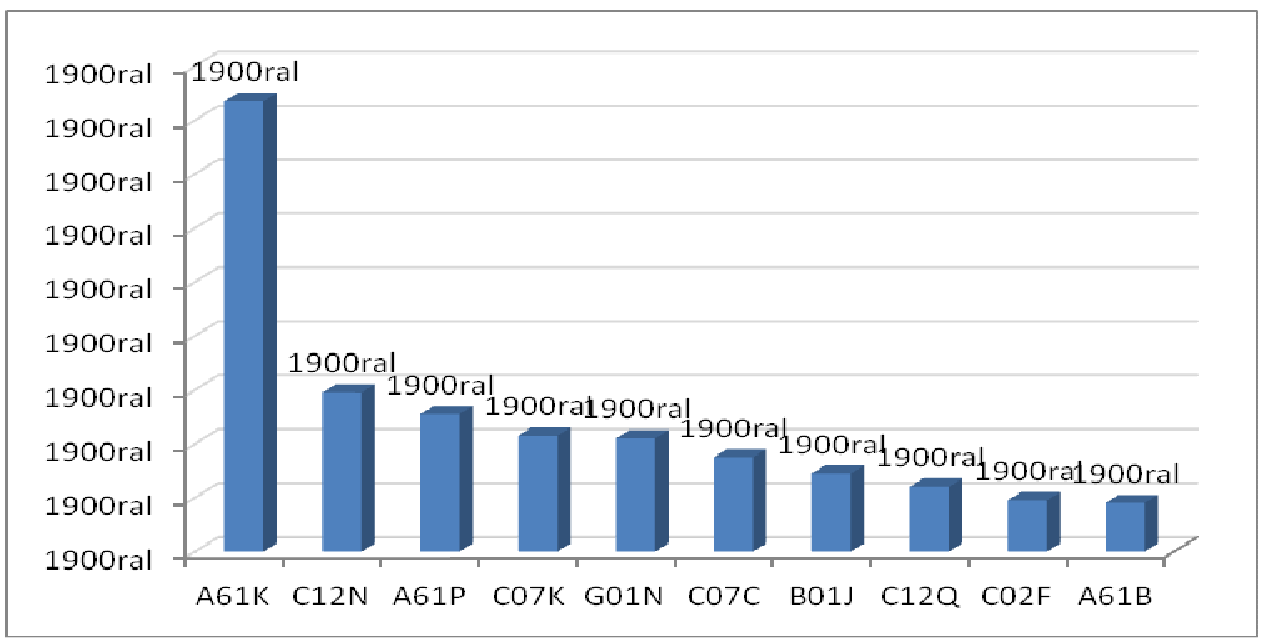

Gráfico 4 - Assuntos de Interesse de proteção

Fonte: Elaboração própria a partir dos dados recuperados na base de patentes do INPI.

Para a identificação das áreas de interesse no desenvolvimento de tecnologias por parte da UFMG, foram utilizados os códigos da classificação internacional de patentes, limitando-se aos quatro primeiros dígitos. A universidade possui maior concentração de produção de invenções em "Preparações para finalidades médicas, odontológicas ou higiênicas", com 167 depósitos classificados nesse código (A61K). A classe $A$ abrange os assuntos relacionados às "Necessidades Humanas". $O$ código C12N trata de "Micro-organismos ou enzimas; suas composições; preparação, conservação, ou manutenção de micro-organismos; engenharia genética ou de mutações; meios de cultura" e foi utilizado em 59 documentos. Do total de patentes com o código de classificação C12N, quase $40 \%$ são referentes à "Mutação ou engenharia genética; e DNA ou RNA concernentes à engenharia genética, vetores; uso de hospedeiros" (C12N 15/). A classe $C$ abrange os assuntos relacionados à "Química e Metalurgia". 


\subsection{Empresas e instituições parceiras da UFMG}

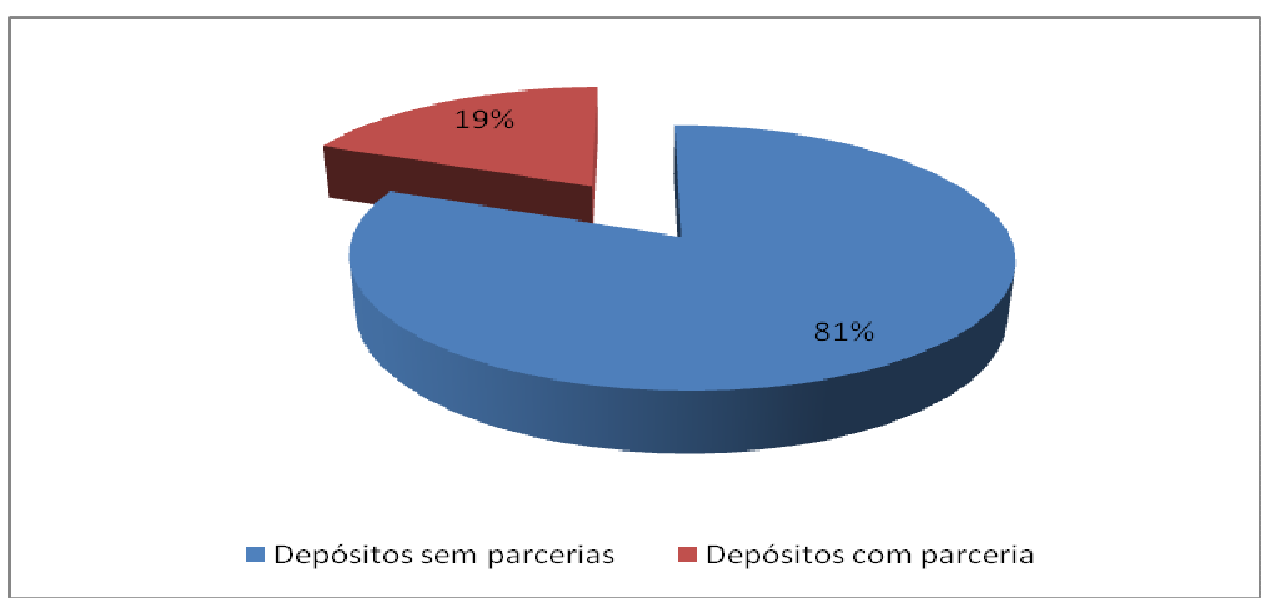

Gráfico 5 - Porcentagem de parcerias

Fonte: Elaboração própria a partir dos dados recuperados na base de patentes do INPI.

O papel da universidade em firmar acordos com empresas públicas e privadas com quem possa desenvolver pesquisas em conjunto ou para licenciar a produção técnico-científica dos pesquisadores para usos comerciais, é uma forma de trazer benefícios para o país, uma vez que dinamiza o processo de produção de conhecimento e pode reduzir custos. Outro benefício gerado pela realização de parcerias é o recebimento por parte da universidade de royalties sobre a comercialização dos produtos e dos serviços criados a partir da pesquisa básica.

A UFMG tem demonstrado maior interesse no desenvolvimento de tecnologias em parceria. Em 2008, apenas 9\% dos desenvolvimentos de tecnologias da UFMG eram realizados em parceria. Em 2012, esse percentual cresceu para $19 \%$, o que indica que a instituição tem considerado as inúmeras vantagens oriundas desse tipo de atuação. A Tabela 1 apresenta a lista de parceiros identificados no presente estudo e o número de documentos de patentes depositados em parceria.

Tabela 1 - Instituições parceiras

\begin{tabular}{l|c|l|c}
\hline \multicolumn{1}{c|}{ Parceiros } & $\begin{array}{c}\text { No. de } \\
\text { Patentes }\end{array}$ & \multicolumn{1}{c|}{ Parceiros } & №. de Patentes \\
\hline FAPEMIG & 30 & EISAI GROUP & 1 \\
\hline CDTN/CNEN & 5 & $\begin{array}{l}\text { ENGENHO 9 } \\
\text { ENGENHARIA } \\
\text { AMBIENTAL }\end{array}$ & 1 \\
\hline CEFET-MG & 4 & FHEMIG & 1 \\
\hline CETEC & 3 & $\begin{array}{l}\text { INSTITUTO } \\
\text { EVANDRO CHAGAS }\end{array}$ & 1 \\
\hline FUNED-MG & 3 & $\begin{array}{l}\text { KATAL } \\
\text { BIOTECNOLOGIA IND } \\
\text { FARMAC }\end{array}$ & 1 \\
\hline FIOCRUZ & 3 & $\begin{array}{l}\text { MUSEU } \\
\text { PARANAENSE } \\
\text { EMILIO GOELDI }\end{array}$ & 1 \\
\hline UFOP & 3 & PETROLEO & 1 \\
\hline
\end{tabular}




\begin{tabular}{|c|c|c|c|}
\hline & & BRASILEIRO S.A & \\
\hline AMATECH & 2 & $\begin{array}{l}\text { SECRETARIA DE } \\
\text { SAUDE PUBLICA DO } \\
\text { ESTADO DO PARA }\end{array}$ & 1 \\
\hline ECOVEC & 2 & $\begin{array}{l}\text { SIGMA } \\
\text { INSTRUMENTOS } \\
\text { LTDA }\end{array}$ & 1 \\
\hline $\begin{array}{l}\text { LUDWIG INSTITUTE } \\
\text { FOR CANCER }\end{array}$ & 2 & $\begin{array}{l}\text { SYNDANSK } \\
\text { UNIVERSITET }\end{array}$ & 1 \\
\hline $\begin{array}{l}\text { MINASFUNGI DO } \\
\text { BRASIL }\end{array}$ & 2 & $\begin{array}{l}\text { UNIAO QUIMICA } \\
\text { FARMACEUTICA } \\
\text { NACIONAL S.A }\end{array}$ & 1 \\
\hline UFV & 2 & UNIGAL LTDA & 1 \\
\hline ANGLO & 1 & UFSJ & 1 \\
\hline ARTECOLA & 1 & UFBA & 1 \\
\hline ASTERMAP & 1 & UFJF & 1 \\
\hline BIOBRAS & 1 & UFSC & 1 \\
\hline BIOLAB & 1 & UFCE & 1 \\
\hline BIOSINTETICA & 1 & UFPA & 1 \\
\hline CEMIG & 1 & UFPR & 1 \\
\hline ELETROBRAS & 1 & UFRJ & 1 \\
\hline CNRS & 1 & $\begin{array}{l}\text { UNIVERSITY OF } \\
\text { SOUTHAMPTON }\end{array}$ & 1 \\
\hline CPPI-PR & 1 & USIMINAS & 1 \\
\hline $\begin{array}{l}\text { CRISTÁLIA PRODUTOS } \\
\text { QUIIMICOS }\end{array}$ & 1 & $\begin{array}{l}\text { VALID } \\
\text { BIOTECNOLOGIA } \\
\text { LTDA }\end{array}$ & 1 \\
\hline $\begin{array}{l}\text { CROMIC INDÚSTRIA E } \\
\text { COMERCIO }\end{array}$ & 1 & & \\
\hline
\end{tabular}

Fonte: Elaboração própria a partir dos dados recuperados na base de patentes do INPI.

Pela análise das parcerias realizadas pela UFMG, percebe-se que $70 \%$ do total de seus parceiros são centros e fundações do poder público. Tais parcerias são responsáveis por um total de $75 \%$ das 84 patentes depositadas em conjunto. A UFMG possui 21 patentes desenvolvidas em conjunto com instituições do setor privado. Esse número representa menos de $5 \%$ do total de patentes da instituição e pode ser um indicativo da dificuldade de comunicação entre os interesses da pesquisa desenvolvida entre os dois tipos de instituição (público e privado).

Essa dificuldade de comunicação é, ainda, mais visível pelo estudo de Nunes e Oliveira (2007), que mapearam os depósitos de patentes das universidades brasileiras de 2000 a 2004. Nesse período, a UNICAMP foi a maior depositante de patentes no INPI, com 232 depósitos, seguida pela UFMG, com 97 depósitos. Os próximos lugares não apresentam tamanha disparidade: UFRJ (81 depósitos) e USP ( 80 depósitos). Isso aponta para a necessidade de maior atenção à inovação e aos inventos gerados pelos pesquisadores da UFMG. Aponta, também, para uma nova percepção dos benefícios que as parcerias podem trazer à instituição. 


\subsection{Pesquisadores inventores da UFMG}

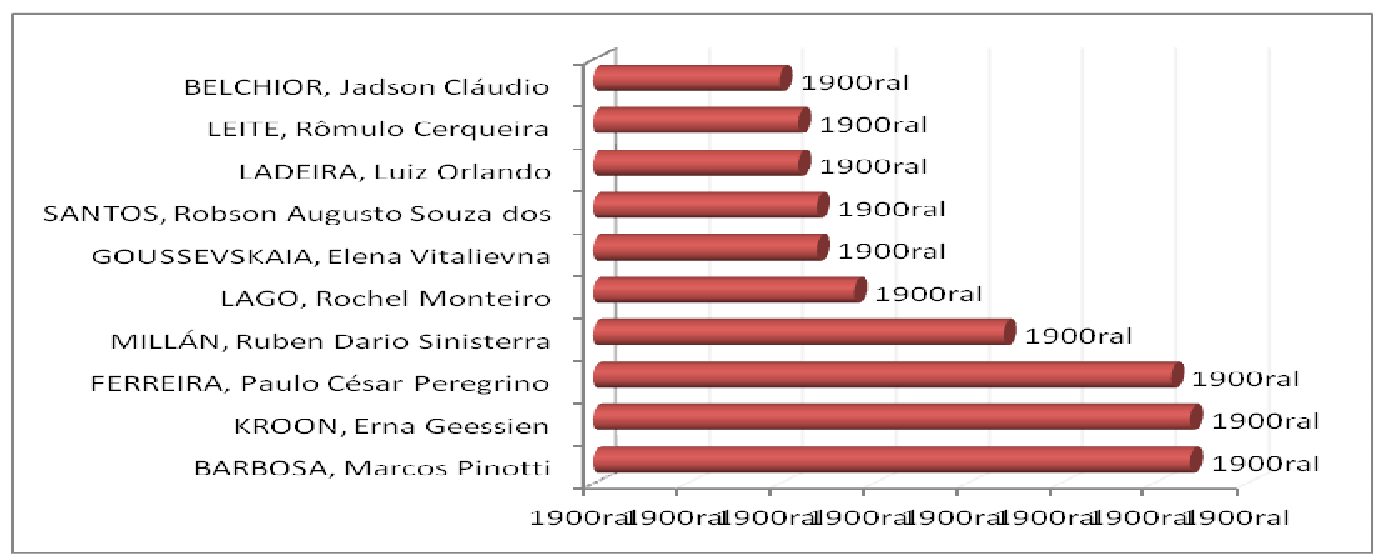

Gráfico 6 - Pesquisadores inventores da UFMG

Fonte: Elaboração própria a partir dos dados recuperados na base de patentes do INPI.

Os Departamentos de Engenharia Mecânica e de Microbiologia são os departamentos que mais protegem o conhecimento gerado por seus pesquisadores. Do Departamento de Engenharia Mecânica, é o pesquisador Marcos Pinotti Barbosa que possui 32 pedidos de patentes e do Departamento de Microbiologia são os pesquisadores Erna Geessien Kroon e Paulo César Peregrino Ferreira, que têm um total de 32 e 31 depósitos, respectivamente. Os pesquisadores Ruben Dario Sinisterra Mílan, Rochel Montero Lago, Elena Vitalievna Goussevskaia e Jadson Claudio Belchior são do Departamento de Química e possuem 22, 14, 12 e 10 depósitos, respectivamente.

Conhecer os atores responsáveis pelo invento de tecnologias de áreas de interesse da empresa é um importante passo na hora de firmar parcerias, contratar consultores ou mesmo de tentar um recrutamento. $\mathrm{O}$ capital intelectual é um dos bens responsáveis pela competitividade empresarial, pois os recursos humanos são os principais responsáveis pelo desempenho das empresas e constituem vantagens competitivas, em um mercado cada vez mais exigente.

Como mencionado anteriormente, o aumento do nível de competitividade tornou necessário que a observância ao negócio de concorrentes se transformasse em uma prática constante. As práticas dos atores envolvidos, em toda a cadeia de mercado, direcionam os negócios uns dos outros, em maior ou menor escala. As empresas precisam tornarse mais competitivas e com melhor capacidade decisória.

As informações contidas em documentos de patentes se revelaram de fundamental importância para o desenvolvimento de atividades de IC, visto que essas informações, em sua grande maioria, não estarão disponíveis em outro tipo de publicação.

A padronização, a confiabilidade e a abrangência dos documentos de patentes são fatores que privilegiam esse tipo de documento em seu uso para práticas de IC e os ressaltam como instrumentos únicos para identificação do estado da técnica das mais diversas tecnologias. 
Aponta-se, como fator de maior atenção, a pouca interação entre os departamentos da UFMG e a pouca interação da universidade com empresas para a efetivação de parcerias, embora exista a preocupação desta com o mercado.

Essa preocupação foi percebida pelo fato da UFMG estar atenta ao licenciamento de suas tecnologias e comercialização das inovações desenvolvidas internamente, por meio da Coordenadoria de Transferência de Inovação e Tecnologia.

\section{Considerações finais}

O presente trabalho buscou apresentar a estrutura e fluxo do processo de patentes, e sua relevância em atividades de Inteligência Competitiva (IC). As patentes se apresentam como fontes privilegiadas de informações precisas e atuais, minimizando o risco na tomada de decisões e investimentos em pesquisa, constituindo-se em um instrumento eficaz para obtenção de vantagem competitiva. Foram apresentadas, dentre as inúmeras ferramentas que suportam a IC, as informações tecnológicas encontradas em documentos de patentes, tais como insumos primordiais para a detecção de informações que prospectam, monitoram e suportam a inovação nas organizações.

Para ilustrar e exemplificar a relevância das patentes no contexto da produção acadêmica, também se apresentou um estudo da proteção de tecnologias pela UFMG, no período de 1989 até 2012, estudo este que aponta o avanço significativo desse procedimento, por parte da instituição, ao longo dos anos.

Dada a importância do tema e sua imbricação com os processos de inovação, tão estimulados na atualidade pelas agências de fomento, coloca-se, como desejável e um possível trabalho futuro dos autores, a realização de estudos mais aprofundados sobre as citações das patentes da UFMG, para que sejam visualizadas as redes de atores e de colaboração e as formas de apropriação e utilização das tecnologias, dentre os pesquisadores da Universidade.

\section{Referências}

BRASIL. Congresso Nacional. Lei no 9.279, de 14 de maio de 1996. Regula direitos e obrigações relativos à propriedade industrial. Diário Oficial da União, Poder Executivo, Brasília, DF, 15 maio 1996.

CASTRO, J. O. C. de. Gerenciando com inteligência. Instituto Sagres. Disponível em: <http://www.sagres.org.br/novo/default.php?page=castro > Acesso em: 6 set. 2007.

COELHO, G. M. et al. Inteligência Competitiva em rede apoiando a estratégia da empresa. In: CONGRESSO INTERNACIONAL DAS INSTITUIÇÕES DE PESQUISA TECNOLÓGICA, 16., Porto Alegre, 2002. Anais... Porto Alegre: CIENTEC, 2002. p. 1-14. Disponível em: 
$<$ http://www.intgas.int.gov.br/Upload//46 monitoramento.pdf $>$. Acesso em: 22 set. 2007.

DOU, $\mathrm{H}$. et al. Patent analysis for competitive technical intelligence and innovative thinking. Data Science Journal, v. 4, p. 209-237, dez. 2005.

FEDERMAN, S. R. Patentes: desvendando seus mistérios. Rio de Janeiro: Qualitymark, 2006.

GOMES, E. B. P.; BRAGA, F. dos R. Inteligência competitiva: como transformar informação em um negócio lucrativo. Rio de Janeiro: Campus, 2001.

GOMES, E. B. P.; BRAGA, F. dos R. Inteligência competitiva no Brasil: uma realidade corporativa. Puzzle - Revista Hispana de la Inteligencia Competitiva, Barcelona, ano 6, n. 23, ago./out. 2006. Disponível em: <http://www.revista-puzzle.com>. Acesso em: 12 maio 2007.

GULLO, L. M. G.; GUERRANTE, R. di S. Maiores depositantes de pedidos de patente no Brasil, com prioridade brasileira. (Publicados entre 1999 e 2003). Rio de Janeiro: INPI, 2004.

KUPFER, D.; TIGRE, P. B. Prospecção tecnológica. In: CARUSO, L. A. C.; TIGRE, P. B. (Coord.). Modelo SENAI de prospecção: documento metodológico. Montevideo: Cintefor/OIT, 2004. p. 17-35.

LODI, C. F. G. Planejamento por cenários e inteligência competitiva: integrando seus processos para tomar decisões estratégicas mais eficazes. In: STAREC, C.; GOMES, E. B. P.; CHAVES, J. B. L. Gestão estratégica da informação e inteligência competitiva. São Paulo: Saraiva, 2005. p. 124142.

MOGEE, M. E. Patent and technology intelligence. In: ASHTON, W. B.; KLAVANS, Richard A. (Eds.). Keeping Abreast of Science and Technology: technical intelligence for business. Columbus, $\mathrm{OH}$ : Battelle Press, 1997. p. 295-335.

NUNES, J. da S.; OLIVEIRA, L. G. de. Universidades brasileiras: utilização do Sistema de Patentes de 2000 a 2004. Rio de Janeiro: INPI, 2007.

OLIVEIRA, L. G. et al. Informação de patentes: ferramenta indispensável para a pesquisa e o desenvolvimento tecnológico. Quim. Nova, v. 28, supl., p. S36-S40, 2005.

PASSOS, A. Inteligência competitiva: como fazer IC acontecer na sua empresa. São Paulo: LCTE, 2005.

PINHEIRO, L. V. R. Inteligência competitiva como disciplina da Ciência da Informação e sua trajetória e evolução no Brasil. In: STAREC, C.; GOMES, E. B. P.; CHAVES, J. B. L. Gestão estratégica da informação e inteligência competitiva. São Paulo: Saraiva, 2005. p. 17-32.

QUEYRAS, J.; QUONIAM, L. Inteligência competitiva. In: TARAPANOFF, K. (Org.). Inteligência, informação e conhecimento em corporações. Brasília: IBICT; UNESCO, 2006. p. 73-98. 
VALENTIM, M. L. P. et al. O processo de inteligência competitiva em organizações. DataGramaZero, v. 4, n. 3, jun. 2003. Disponível em: <http://www.dgz.org.br/jun03/F | art.htm>. Acesso em: 12 fev. 2007.

WORLD INTELLECTUAL PROPERTY ORGANIZATION (WIPO). World Intellectual Property Indicators. 2011. Disponível em: <http://www.wipo.int/ipstats/en/wipi/index.html>. Acesso em: 6 dez. 2012. 